\title{
JURNAL PENELITIAN KEPERAWATAN
}

\author{
Volume 5, No. I, Januari 2019
}

Hubungan Response Time Perawat dengan Tingkat Kepuasan Pasien BPJS di Instalasi Gawat Darurat

Hubungan Tipe Kepribadian dengan Partisipasi Belajar Kelompok Mahasiswa Prodi Ners

Penggunaan Metode Simulasi dalam Peningkatan Critical Thinking: Literature Review

Pentingnya Self-Directed Learning Readiness (SDLR) Terhadap Motivasi Belajar, Manajemen Diri dan Pengendalian Diri pada Mahasiswa Kesehatan: A Literature Review

Metode Massage terhadap Tekanan Darah pada Penderita Hipertensi: A Literatur Review

Pengaruh Permainan Ular Tangga terhadap Perilaku Hidup Bersih dan Sehat (PHBS) pada Anak Sekolah Dasar

Penilaian Tumbuh Kembang dengan Dukungan Anticipatory Guidance pada Anak di Tempat Penitipan Anak

Hubungan Kadar Gula Darah Sewaktu dengan Gejala Neuropati Perifer Penderita Diabetes Melitus Tipe 2

Pengalaman Remaja Saat Menghadapi Manarche

Adaptasi Psikologis pada Ibu Post Partum Primigravida (Fase Taking Hold) Sectio Caesarea dan Partus Normal

Diterbitkan oleh

STIKES RS. BAPTIS KEDIRI

\begin{tabular}{|c|c|c|c|c|c|}
\hline $\begin{array}{c}\text { Jurnal Penelitian } \\
\text { Keperawatan }\end{array}$ & Vol.5 & No.1 & $\begin{array}{c}\text { Hal } \\
1-87\end{array}$ & $\begin{array}{c}\text { Kediri } \\
\text { Januari 2019 }\end{array}$ & 2407-7232 \\
\hline
\end{tabular}




\title{
JURNAL PENELITIAN KEPERAWATAN
}

\author{
Volume 5, №. I, Januari 2019
}

\author{
Penanggung Jawab \\ Aries Wahyuningsih, S.Kep., Ns., M.Kes
}

Ketua Penyunting

Srinalesti Mahanani, S.Kep., Ns., M.Kep

\section{Sekretaris}

Desi Natalia Trijayanti Idris, S.Kep., Ns., M.Kep

\section{Bedahara}

Dewi Ika Sari H.P., SST., M.Kes

\section{Penyunting Ahli:}

Dr. Titih Huriah, S.Kep., Ns., M.Kep., Sp.Kom

Penyunting Pelaksana

Aries Wahyuningsih, S.Kep., Ns., M.Kes

Tri Sulistyarini, A.Per Pen., M.Kes

Dewi Ika Sari H.P., SST., M.Kes

Erlin Kurnia, S.Kep., Ns., M.Kes

Dian Prawesti, S.Kep., Ns., M.Kep

Maria Anita Yusiana, S.Kep., Ns., M.Kes

\section{Sirkulasi}

Heru Suwardianto, S.Kep., Ns M.Kep

\section{Diterbitkan Oleh:}

STIKES RS. Baptis Kediri

Jl. Mayjend Panjaitan No. 3B Kediri

Email: uuptppmstikesbaptis@gmail.com

Link: http://jurnalbaptis.hezekiahteam.com/jurnal 


\title{
JURNAL PENELITIAN KEPERAWATAN
}

\author{
Volume 5, №. I, Januari 2019
}

\section{DAFTAR ISI}

Hubungan Response Time Perawat dengan Tingkat Kepuasan Pasien BPJS di Instalasi Gawat Darurat

Samfriati Sinurat | Indra Hizkia Perangin-angin | Josephine Christabel Lombu Sepuh

Hubungan Tipe Kepribadian dengan Partisipasi Belajar Kelompok Mahasiswa Prodi Ners

Lilis Novitarum | Mardiati Barus | Timo Rauli Lumban Gaol

Penggunaan Metode Simulasi dalam Peningkatan Critical Thinking: Literature Review

Achmad Vindo Galaresa | Sri Sundari

Pentingnya Self-Directed Learning Readiness (SDLR) Terhadap Motivasi Belajar, Manajemen Diri dan Pengendalian Diri pada Mahasiswa Kesehatan: $A$ Literature Review

Wahyu Riyaningrum | Wiwik Kusumawati

Metode Massage terhadap Tekanan Darah pada Penderita Hipertensi: A Literatur Review

Ardiansyah | Titih Huriah

Pengaruh Permainan Ular Tangga terhadap Perilaku Hidup Bersih dan Sehat (PHBS) pada Anak Sekolah Dasar

Dhita Kris Prasetyanti | Galuh Pradian Yanuaringsih

Penilaian Tumbuh Kembang dengan Dukungan Anticipatory Guidance pada Anak di Tempat Penitipan Anak

Sandy Kurniajati | Kili Astarani | Dewi Ika Sari Hari Poernomo

Hubungan Kadar Gula Darah Sewaktu dengan Gejala Neuropati Perifer 61-66 Penderita Diabetes Melitus Tipe 2

Supriyadi | Susmini

Pengalaman Remaja Saat Menghadapi Manarche

$67-75$

Lilik Setiawan | Sutiyah Heny | Reni Linda Saputri 
Adaptasi Psikologis pada Ibu Post Partum Primigravida (Fase Taking Hold) 76-82 Sectio Caesarea dan Partus Normal

Dian Taviyanda 


\title{
HUBUNGAN RESPONSE TIME PERAWAT DENGAN TINGKAT KEPUASAN PASIEN BPJS DI INSTALASI GAWAT DARURAT
}

\author{
RELATIONSHIPS RESPONSE TIME NURSE WITH LEVEL \\ PATIENT SATISFACTION BPJS IN EMERGENCY DEPARTEMEN
}

\author{
*Samfriati Sinurat, *Indra Hizkia Perangin-angin, **Josephine Christabel Lombu \\ Sepuh \\ * Staf Pengajar STIKes Santa Elisabeth Medan \\ **Program Studi Ners STIKes Santa Elisabeth Medan \\ Email:
}

\begin{abstract}
ABSTRAK
Response Time merupakan kecepatan dalam penanganan pasien oleh perawat $\leq 5$ menit saat tibanya pasien di unit pelayanan kesehatan. Response Time dengan penanganan kecepatan yang sudah berstandar dapat menjadi proses pelayanan yang baik di IGD sehingga pasien dapat merasakan kepuasan dari pelayanan keperawatan. Penelitian ini bertujuan untuk mengetahui hubungan Response Time Perawat dengan Tingkat Kepuasan Pasien BPJS di Instalasi Gawat Darurat Rumah Sakit Santa Elisabeth Medan. Desain penelitian menggunakan rancangan survey analitik dengan metode cross sectional. Teknik pengambilan sampel dalam penelitian ini menggunakan purposive sampling dengan sampel pasien BPJS yang berobat di IGD Rumah Sakit Santa Elisabeth Medan sebanyak 87 responden. Instrumen yang digunakan yaitu lembar observasi Response Time Perawat dan lembar kuesioner Tingkat Kepuasan Pasien. Response Time perawat sebanyak 82,8\% "tepat" yaitu $\leq 5$ menit dan Tingkat Kepuasan pasien BPJS sebanyak 75,9\% "puas". Hasil uji Fisher's Exact didapatkan $p=0,007 \quad(p<0,05)$, menunjukkan ada hubungan Response Time Perawat dengan Tingkat Kepuasan Pasien BPJS di Ruangan IGD Rumah Sakit Santa Elisabeth Medan Tahun 2018. Diharapkan agar Response Time perawat tetap ditingkatkan dalam melakukan tindakan pelayanan dan memodifikasi ruangan yang ada sebagai ruang tunggu keluarga di ruangan IGD untuk meningkatkan mutu pelayanan Rumah Sakit, sehingga tingkat kepuasan pasien lebih baik lagi.
\end{abstract}

Kata Kunci: Response Time, Tingkat Kepuasan Pasien

\section{ABSTRACT}

Response Time is a speed in the handling of patients by nurse $\leq 5$ minutes when the arrival of patients in the health care unit. Response Time with standardized speed handling can be a good service process in the Emergency Installation room so that patients can feel satisfaction from nursing service. This study aims to determine the correlation between Response Time Nurse and BPJS Patient Satisfaction Level at Emergency Installation Santa Elisabeth Hospital Medan. The research design used an analytical survey design with cross sectional method. Sampling technique in this research used purposive sampling with sample patient of BPJS which treatment at Emergency 
Installation Santa Elisabeth Hospital Medan as many as 87 respondents. Instruments used were observation sheets for Nurse Response Time and questionnaires sheet for Patient Satisfaction Level. Response Time majority nurses "exact" ie $\leq 5$ minutes $82.8 \%$ and the level of satisfaction of patients BPJS majority "satisfied" 75.9\%. Fisher's Exact test results obtained $p=0,007(p<0,05)$, indicate there is relation of Response Time Nurse with Level of Satisfaction of Patient of BPJS in Emergency Installation room Hospital of Santa Elisabeth Medan Year 2018. It is expected that Response Time nurse still to be increased in doing service act and modifying the existing room as family waiting room in Emergency Installation room to improve hospital service quality, so that patient satisfaction level better.

\section{Keywords: Response Time, Patient Satisfaction}

\section{Pendahuluan}

Rumah sakit merupakan institusi pelayanan kesehatan yang menyediakan pelayanan rawat inap dan rawat jalan (Menteri Kesehatan RI, 2010). Salah satu yaitu ruangan Instalasi Gawat Darurat yang merupakan unit pelayanan rumah sakit yang memberikan pertolongan pertama dan sebagai jalan pertama masuknya pasien. Pasien yang ditangani di Instalasi Gawat Darurat yaitu peserta Jaminan Kesehatan Sosial dan Non Jaminan Kesehatan Sosial. Asuransi Kesehatan merupakan lembaga sosial yang bergerak di bidang pengusahaan jaminan pelayanan kesehatan dan mengatur hak dan kewajiban peserta. Badan Penyelenggara Jaminan Sosial (BPJS) merupakan salah satu jenis asuransi.

BPJS merupakan lembaga penyelenggara jaminan sosial yang mencakup seluruh penduduk Indonesia dengan memberikan pelayanan kesehatan yang komprehensif dengan prinsip asuransi sosial, dimana peserta yang mampu membayar iuran, yang miskin dan tidak mampu dibayar iurannya oleh pemerintah.

Dengan BPJS seseorang yang mengalami sakit, kecelakaan dan kematian mendapatkan pelayanan perlindungan keuangan atau financial protection sehingga tidak mengalami kesulitan biaya (Ulinuha, 2014). Kepuasan pelanggan menjadi salah satu indikator kinerja klinis pelayanan di IGD. Karena kepuasan pasien merupakan tingkat perasaan setelah membandingkan kinerja yang ia rasakan atau hasil yang dirasakan dibandingkan dengan harapan. Tidak semua bisa merasakan yang diberikan meskipun sudah diberikan pelayanan kesehatan (Rimawati, dkk. 2016).

Kaban (2015) mengatakan bahwa di rumah sakit metropolitan St. Louis mid Missouri di Amerika Serikat tentang kualitas pelayanan keperawatan dengan kepuasan pasien mendapat hasil 50\% pasien tidak merasa puas terhadap pelayanan yang diberikan dimana pelayanan yang diberikan perawat kadang terlambat pada dimensi (responsiveness). Hasil penelitian menunjukkan bahwa dari 10 orang pasien yang berkunjung ke UGD, diketahui enam orang $(60 \%)$ mengeluhkan tentang pelayanan. Dimana pelayanan perawatan yang diberikan tidak sesuai dengan harapan, waktu tunggu yang relatif lama dan fasilitas/alat yang ada serta pegawai yang masih kurang. Sementara empat orang lainnya $(40 \%)$ mengatakan ketidakpuasannya mengenai obat yang diberikan relatif lama dan memiliki proses yang rumit.

Sondari (2017) mengatakan bahwa di RSUD Kabupaten Brebes ada 2 dimensi dari 5 dimensi kepuasan pasien yang kurang puas terhadap pelayanan program jaminan kesehatan yaitu dimensi Reliabilty $(88,8 \%)$ dan Tangible (90,1\%). Akhir-akhir ini Liputan 6 
(2017) kasus ketidakpuasan pasien bayi Deborah yang tidak tertolong dan berujung pada kematian karena terlambat ditangani oleh RS Mitra Keluarga Kalideres Jakarta Barat. Setelah dilakukan tindakan pertolongan pertama oleh tim medis, dokter menyebutkan bahwa Deborah harus segera dibawa ke ruang PICU dan harus membayar uang muka. Namun orangtua Deborah hanya memberikan kartu BPJS. Pihak RS menolak dan meminta orangtua Deborah untuk merujuk ke RS yang menerima BPJS.

Inilah kasus ketidakpuasan pelayanan. Dalam konteks kepuasan pasien ini dikaitkan dengan kualitas pelayanan yang diukur dengan metode SERVQUAL yang dikembangkan oleh Parasuraman yang terdiri dari lima dimensi yaitu Responsiveness (daya tanggap); Assurance (jaminan); Tangible (bukti fisik); Empathy (empati); Reliability (keandalan) (Nursalam, 2016). Ketidakpuasan pelayanan sangat berpengaruh pada kecepatan dan ketepatan pelayanan menjadi standart pelayanan minimal yang harus dicapai oleh petugas khususnya perawat di IGD. Waktu tanggap (response time) pelayanan dapat dihitung dengan hitungan menit dan sangat dipengaruhi oleh berbagai hal baik mengenai jumlah tenaga maupun komponen-komponen lain yang mendukung seperti pelayanan laboratorium, radiologi, farmasi, dan administrasi. Response time dikatakan tepat apabila waktu yang diperlukan tidak melebihi waktu rata-rata standar yang ada. (Hutapea, 2017).

Response time merupakan kecepatan dalam penanganan pasien, dihitung sejak pasien datang sampai adanya tanggapan dari perawat (Suhartati, 2011). Response Time (waktu tanggap) adalah suatu standar pelayanan yang harus dimiliki oleh Instalasi Gawat Darurat. Waktu tanggap yang baik bagi pasien yaitu $\leq 5$ menit (Keputusan Menteri Kesehatan Republik Indonesia, 2009). Dari pengamatan yang saya lakukan di IGD Rumah Sakit Santa Elisabeth Medan terkait response time perawat, ada 3 perawat yang response timenya saya observasi, 2 dari 3 diantaranya memiliki waktu respon yang $>5$ menit. Berdasarkan data dari rekam medis Rumah Sakit Santa Elisabeth Medan, ada 10.889/tahun pasien BPJS yang berobat ke IGD RS Santa Elisabeth Medan (Rekam Medis RSE, 2017). Dari wawancara yang saya lakukan kepada 5 orang pasien peserta jaminan sosial yang berobat di IGD, ada 2 orang yang merasa tidak puas terhadap pelayanan rumah sakit karena lamanya menunggu dibagian administrasi pada dimensi reliability, dan 1 orang tidak puas terhadap pelayanan yang diberikan dimana pelayanan yang diberikan perawat kadang terlambat pada dimensi (responsiveness). Sedangkan 2 orang lainnya merasa puas.

Berdasarkan latar belakang di atas, maka peneliti tertarik untuk melakukan penelitian mengenai Hubungan Response Time Perawat Dengan Tingkat Kepuasan Pasien BPJS (Badan Penyelenggara Jaminan Sosial) di Ruangan IGD Rumah Sakit Santa Elisabeth Medan Tahun 2018.

\section{Metodologi Penelitian}

Desain penelitian menggunakan rancangan survey analitik dengan metode cross sectional. Teknik pengambilan sampel dalam penelitian ini menggunakan purposive sampling dengan sampel pasien BPJS yang berobat di IGD Rumah Sakit Santa Elisabeth Medan pada 22 Februari-10 Maret 2018 sebanyak 87 orang dan perawat yang bertugas di IGD sebanyak 21 orang.

Instrumen yang digunakan yaitu lembar observasi response time perawat dan kuesioner tingkat kepuasan pasien yang terdiri dari 23 pernyataan yang telah divalidasi dengan nilai $r=0,374$ dan realibilitas cronbach alpha 0,943 . Lembar observasi digunakan untuk mengukur kecepatan waktu tanggap dalam satuan menit.

Analisa data untuk melakukan analisis korelasi digunakan rumus 
korelasi Product Moment dari Pearson dimana jika perolehan nilai $p$ hitung
$<0,05$ yang menandakan bahwa ada hubungan yang signifikan.

\section{Hasil Penelitian}

Analisa Univariat

Tabel 1. Distribusi Frekuensi Responden Berdasarkan Umur, Jenis Kelamin, Tingkat Pendidikan, dan Suku Pasien BPJS di Instalasi Gawat Darurat Tahun $2018(n=87)$.

\begin{tabular}{llcc}
\hline \multicolumn{1}{c}{ Variabel } & \multicolumn{1}{c}{ Kategori } & $\boldsymbol{F}$ & $\mathbf{\%}$ \\
\hline Umur & $0-5$ balita & 6 & 6,9 \\
& $5-11$ kanak-kanak & 0 & 0 \\
& $12-16$ remaja awal & 4 & 4,6 \\
& $17-25$ remaja akhir & 8 & 9,2 \\
& $26-35$ dewasa awal & 11 & 12,6 \\
& $36-45$ dewasa akhir & 10 & 11,5 \\
& $46-55$ lansia awal & 9 & 10,3 \\
& 56-65 lansia akhir & 13 & 14,9 \\
& $>65$ manula & 26 & 29,9 \\
\hline Total & & $\mathbf{8 7}$ & $\mathbf{1 0 0 \%}$ \\
\hline Jenis Kelamin & Laki-laki & 39 & 44,8 \\
& Perempuan & 48 & 55,2 \\
\hline Total & & $\mathbf{8 7}$ & $\mathbf{1 0 0 \%}$ \\
\hline Tingkat & Tidak Sekolah & 10 & 11,5 \\
Pendidikan & SD & 18 & 20,7 \\
& SMP & 16 & 18,4 \\
& SMA/Sederajat & 16 & 18,4 \\
& Diploma/Akademik & 15 & 17,2 \\
& Sarjana/PT & 12 & 13,8 \\
\hline Total & & $\mathbf{8 7}$ & $\mathbf{1 0 0 \%}$ \\
\hline Suku & Toba & 52 & 59,8 \\
& Karo & 22 & 25,3 \\
& Simalungun & 5 & 5,7 \\
& Nias & 3 & 3,4 \\
& Jawa & 2 & 2,3 \\
& Dll & 3 & 3,4 \\
\hline & & $\mathbf{8 7}$ & $\mathbf{1 0 0 \%}$ \\
\hline & & &
\end{tabular}

Tabel.1 Menyatakan bahwa segi umur menunjukkan dari 87 responden, didapatkan umur responden yang paling banyak yaitu $>65$ tahun manula sebanyak 26 orang $(29,9 \%)$, diikuti umur 56-65 tahun lansia akhir sebanyak 13 orang $(14,9 \%)$, dan umur yang paling sedikit yaitu 12-16 tahun remaja awal sebanyak 4 orang $(4,6 \%)$. Jenis kelamin yang paling banyak berobat di IGD didapatkan perempuan sebanyak 48 orang $(55,2 \%)$, dan yang paling sedikit yaitu laki-laki sebanyak 39 orang (44,8\%). Pada tingkat pendidikan yang paling banyak berobat yaitu SD sebanyak 18 orang $(20,7 \%)$, dan tingkat pendidikan paling sedikit yaitu Tidak Sekolah sebanyak 10 orang $(11,5 \%)$ Dalam hal segi suku didapatkan bahwa suku yang paling banyak berobat yaitu suku Toba sebanyak 52 orang $(59,8 \%)$, dan suku yang paling sedikit berobat yaitu suku Jawa sebanyak 2 orang $(2,3 \%)$. 
Tabel 2. Distribusi Frekuensi $(f)$ dan persentase Response Time Perawat pada Pasien BPJS (n=87).

\begin{tabular}{lccc}
\hline & Response Time & $\boldsymbol{f}$ & $\mathbf{\%}$ \\
\hline Tepat $\leq 5$ menit & 72 & $82,8 \%$ \\
Tidak Tepat $>5$ menit & 15 & $17,2 \%$ \\
\hline Total & $\mathbf{8 7}$ & $\mathbf{1 0 0 \%}$ \\
\hline
\end{tabular}

Dari hasil observasi peneliti yang menggunakan stopwatch didapatkan bahwa response time perawat dalam menanggapi sejak pasien datang di pintu IGD sampai adanya tanggapan atau respon dari perawat dengan waktu yang baik yaitu $\leq 5$ menit sebanyak 72 orang $(82,8 \%)$, dan yang tidak tepat $>5$ menit sebanyak 15 orang $(17,2 \%)$.

Tabel 3. Distribusi Frekuensi ( $f$ ) dan persentase Kepuasan Pasien BPJS di Ruangan Instalasi Gawat Darurat Tahun 2018 ( $(n=87)$.

\begin{tabular}{lccc}
\hline & Kepuasan & $\boldsymbol{f}$ & $\mathbf{\%}$ \\
\hline Tidak Puas & 21 & $24,1 \%$ \\
Puas & 66 & $75,9 \%$ \\
\hline Total & $\mathbf{8 7}$ & $\mathbf{1 0 0 \%}$ \\
\hline
\end{tabular}

Berdasarkan tabel 3 dari hasil penelitian yang dilakukan pada 87 responden untuk kepuasan pasien BPJS didapatkan yang tidak puas sebanyak 21 orang $(24,1 \%)$, dan yang puas sebanyak
66 orang $(75,9 \%)$. Hal ini dapat dilihat dari hasil kuesioner yang diberikan kepada pasien BPJS di Ruangan Instalasi Gawat Darurat Rumah Sakit Santa Elisabeth Medan.

\section{Analisa Bivariat}

Tabel 4. Tabulasi Silang Hubungan Response Time Perawat dengan Tingkat Kepuasan Pasien BPJS ( $\mathbf{n}=87)$.

\begin{tabular}{|c|c|c|c|}
\hline Response Time & Tidak Puas & Puas & Fisher's Exact Test \\
\hline Tepat $\leq 5$ menit & 13 & 59 & 0007 \\
\hline Tidak Tepat $>5$ menit & 8 & 7 & 0,007 \\
\hline
\end{tabular}

Berdasarkan hasil uji Fisher's Exact didapatkan hasil p value 0,007 dimana $\mathrm{p}<0,05$. Hasil uji tersebut didapatkan Ha diterima yang berarti ada Hubungan Response Time Perawat Dengan Pasien BPJS (Badan Penyelenggara Jaminan Sosial) di Ruangan IGD Rumah Sakit Santa Elisabeth Medan Tahun 2018.

\section{Pembahasan}

Response Time Perawat pada pasien BPJS di Ruangan Instalasi Gawat Darurat Tahun 2018

Pada hasil penelitian yang dilakukan oleh peneliti di IGD Rumah Sakit Santa Elisabeth Medan mengenai response time perawat pada pasien BPJS, yang dilakukan dengan menggunakan 
stopwatch yang menunjukkan waktu tanggap atau respon perawat pada saat pasien datang ke IGD dengan waktu yang tepat $\leq 5$ menit sebanyak 72 orang $(82,8 \%)$, dan waktu yang tidak tepat $>5$ menit sebanyak 15 orang (17,2\%). Response time perawat $>5$ menit atau pelayanan lambat kemungkinan dapat disebabkan masih ada perawat yang merespon pasien lambat, kualitas pelayanan jasa yang diberikan perawat kepada pasien masih dirasa kurang oleh pasien, serta keterbatasan sarana dan prasarana rumah sakit yang kurang memadai dibandingkan jumlah pasien yang tiba dalam waktu bersamaan di IGD sehingga perawat lebih memprioritaskan masalah yang paling mengancam jiwa.

Hal ini didukung oleh penelitian yang dilakukan Pisu (2015) yang menyatakan bahwa response time dapat dipengaruhi keterbatasan jumlah perawat, pergantian shift jaga dan prasarana yang kurang memadai dengan jumlah pasien yang masuk, serta beberapa pasien yang tiba diwaktu bersamaan, sehingga perawat lebih memprioritaskan masalah pasien yang paling darurat. Menurut Suhartati (2011), Response time merupakan kecepatan dalam penanganan pasien, dihitung sejak pasien datang sampai adanya tanggapan dari perawat. Waktu tanggap yang baik bagi pasien yaitu $\leq 5$ menit (Keputusan Menteri Kesehatan Republik Indonesia, 2009). Kecepatan perawat dalam memberikan response time dipengaruhi beberapa faktor-faktor yaitu faktor internal dan faktor eksternal. Faktor internal terdapat dalam diri seorang perawat atau petugas yang lainnya seperti perawat yang mahir dalam melakukan tindakan keperawatan dan triase, dan kecepatan dalam menanggapi pasien. Faktor eksternal yaitu dimana perawat lebih mementingkan pasien yang gawat darurat sehingga pasien yang tidak gawat darurat tidak diutamakan, atau tenaga kesehatan yang kurang, perawat yang harus mengantar pasien ke ruangan lain karena tidak memiliki petugas khusus untuk mobilisasi pasien.
Rumah Sakit Santa Elisabeth Medan mempunyai Standar Pelayanan Minimal (SPM) di IGD berupa response time $\leq 5$ menit. Dalam mencapai SPM tersebut, dilakukan program yaitu dengan memenuhi ketenagaan di IGD, memenuhi sarana dan prasarana. Jadi, dari hasil penelitian yang dilakukan peneliti dan berdasarkan teori yang ada maka penempatan perawat di triase saat pasien baru datang sangat menjamin ketepatan dan kecepatan response time perawat dalam hal penanganan pasien.

\section{Tingkat Kepuasan Pasien BPJS di Ruangan Instalasi Gawat Darurat}

Hasil penelitian yang dilakukan oleh peneliti di Rumah Sakit Santa Elisabeth Medan ditemukan pasien yang menjadi responden kepuasan kategori puas sebanyak 66 orang $(75,9 \%)$. Pasien puas dikarenakan pelayanan yang diberikan perawat dan respon perawat dalam menanggapi keluhan dilakukan dengan cepat dan tepat, dimana pelayanan diterima sesuai dengan harapan pasien. Maka dapat diketahui dari 87 responden didapatkan pasien yang puas 66 orang dengan persentase $75,9 \%$, dan yang tidak puas 21 orang dengan persentase $24,1 \%$. Pasien yang tidak puas kemungkinan disebabkan oleh pelayanan yang diterima tidak sesuai dengan harapan pasien, dan lamanya perawat menangani keluhan pasien, dapat juga disebabkan karena kurangnya fasilitas seperti ruang tunggu untuk keluarga yang sedang menemani pasien.

Kepuasan adalah persepsi terhadap produk atau jasa yang telah memenuhi harapannya. Ada beberapa faktor yang mempengaruhi kepuasan pasien yaitu, kualitas produk atau jasa dimana pasien merasa puas bila jasa yang didapatkan berkualitas, emosional dimana pasien merasa yakin dan kagum terhadap suatu institusi pelayanan kesehatan, kinerja dimana pasien dapat menikmati kinerja perawat yang cepat dan nyaman, estetika merupaka daya tarik suatu institusi, 
karakteristik produk meliputi penampilan bangunan, kebersihan, pelayanan keramahan petugas, lokasi, fasilitas kesehatan baik sarana dan prasarana (ruang tunggu, tempat parkir), komunikasi, suasana yang tenang dan nyaman (Nursalam, 2016). Hal ini didukung oleh penelitian yang dilakukan Pisu (2015) yang menyatakan bahwa kepuasan pasien berkaitan erat dengan mutu pelayanan keperawatan yang diberikan kepada pasien serta ketepatan dan kecepatan memberikan pelayanan menunjang tingkat kepuasan pasien.

Berdasarkan hasil penelitian yang dilakukan terhadap kepuasan pasien BPJS di IGD Rumah Sakit Santa Elisabeth Medan dan dari hasil penelitian yang dilakukan oleh peneliti sebelumnya, pelayanan haruslah dipertahankan dan ditingkatkan agar kualitas pelayanan dapat berjalan sesuai harapan pasien, dan dapat meningkatkan mutu pelayanan keperawatan, yang diberikan perawat kepada pasien serta ketepatan dan kecepatan memberikan pelayanan menunjang tingkat kepuasan pasien, agar kualitas pelayanan keperawatan yang profesional dan memuaskan bagi pengguna jasa dapat diwujudkan.

\section{Response Time Perawat dengan Tingkat Kepuasan Pasien BPJS di Ruangan Instalasi Gawat Darurat Tahun 2018}

Hasil uji statistik Fisher's Exact menunjukan bahwa dari 87 responden, diperoleh nilai $p=0,007$, dengan demikian $\mathrm{Ha}$ diterima berarti ada hubungan yang signifikan antara Response Time perawat dengan Tingkat Kepuasan Pasien BPJS (Badan Penyelenggara Jaminan Sosial) di Ruangan IGD Rumah Sakit Santa Elisabeth Medan Tahun 2018.

Maatilu (2014) mengatakan salah satu indikator keberhasilan penanggulangan medik penderita gawat darurat adalah kecepatan memberikan pertolongan yang memadai kepada penderita gawat darurat baik pada keadaan rutin sehari-hari atau sewaktu bencana.

Hasil Penelitian Pisu (2015) untuk mengetahui hubungan response time perawat dengan tingkat kepuasan pasien, Pisu melakukan penelitian dengan melibatkan pasien yang datang ke Instalasi Gawat Darurat. Perawat yang melakukan waktu tanggap dengan cepat dan tepat akan mendapat nilai positif dari pasien dan tingkat kepuasan pasien meningkat. Berdasarkan hasil penelitian, bahwa kepuasan pasien BPJS dapat tercapai dari response time perawat yang cepat. Hasil penelitian yang dilakukan oleh peneliti sependapat dengan peneliti sebelumnya yaitu penelitian Pisu (2015) dikatakan bahwa ada hubungan Response Time Perawat dengan Tingkat Kepuasan Pasien BPJS.

Meskipun perawat sudah cepat dalam menangani pasien, tapi masih ada saja pasien yang masih belum puas dikarenakan keterbatasan sarana dan prasarana rumah sakit dan perawat lebih memprioritaskan pasien gawat darurat. Pasien yang ditangani $>5$ menit sebanyak 15 orang $(17,2 \%)$ adalah pasien yang yang tidak membutuhkan pertolongan segera atau pasien yang tidak gawat dan tidak darurat, seperti pasien yang tidak membutuhkan penanganan khusus di IGD tapi seharusnya ke poli umum.

Hasil penelitian ini didukung oleh penelitian Pisu (2015) yang menyatakan bahwa pelayanan di IGD dalam memberikan waktu tanggap dianggap sudah cepat tetapi masih ada dari total responden yang mengakui bahwa response time perawat masih lambat. Dikarenakan masih ada perawat yang merespon pasien lambat, kualitas pelayanan jasa yang diberikan perawat kepada pasien masih dirasa kurang oleh pasien, serta keterbatasan sarana dan prasarana rumah sakit yang kurang memadai dibandingkan jumlah pasien yang tiba dalam waktu bersamaan di IGD sehingga perawat lebih memprioritaskan masalah yang paling darurat, sehingga pelayanan yang diterima oleh pasien lainnya lambat 
karena harus menunggu untuk mendapatkan penanganan, kondisi ini yang menurut persepsi pasien di IGD merasa tidak nyaman, sehingga menyebabkan ketidakpuasan pasien.

Hasil dari penelitian dapat disimpulkan bahwa Response Time Perawat berhubungan dengan Tingkat Kepuasan Pasien BPJS. Dimana kepuasan merupakan persepsi terhadap produk atau jasa yang telah memenuhi harapannya. Berdasarkan dari hasil penelitian Hubungan Response Time Perawat dengan Tingkat Kepuasan Pasien BPJS di IGD Rumah Sakit Santa Elisabeth Medan, menurut peneliti jika hasil kepuasan pasien tinggi terhadap pelayanan, maka pasien yang datang ke IGD Rumah Sakit Santa Elisabeth akan meningkat. Response Time Perawat perlu dipertahankan untuk meningkatkan mutu pelayanan Rumah Sakit terutama di IGD agar pasien puas terhadap pelayanan dan tanggapan atau waktu respon dalam melakukan tindakan.

\section{Kesimpulan}

Response Time perawat IGD Rumah Sakit Santa Elisabeth Medan Tahun 2018 mayoritas memiliki waktu tanggap yang baik $\leq 5$ menit sebanyak 72 orang $(82,8 \%)$. Tingkat Kepuasan pasien BPJS di IGD Rumah Sakit Santa Elisabeth Medan Tahun 2018 mayoritas 66 orang $(75,9 \%)$ pasien merasa puas terhadap waktu tanggap atau respon perawat. Hasil uji Fisher's Exact di dapatkan $\mathrm{p}$ value $=0,007(\mathrm{p}<0,05)$ yang artinya bahwa ada hubungan Response Time perawat dengan Tingkat Kepuasan pasien BPJS di ruangan IGD Rumah Sakit Santa Elisabeth Medan Tahun 2018.

\section{Saran}

Saran bagi Rumah Sakit dan Perawat diharapkan agar rumah sakit dapat memanfaatkan ruangan atau memodifikasi ruangan yang ada untuk dimanfaatkan sebagai ruang tunggu bagi keluarga pasien terkhusus di ruangan IGD, dan diharapkan juga agar perawat lebih meningkatkan response time perawat dalam melakukan waktu tanggap atau respon kepada. Saran bagi Mahasiswa/Mahasiswi diharapkan agar mahasiswa/i dapat mengaplikasikan response time di Rumah Sakit terkhusus di ruangan IGD Rumah Sakit Santa Elisabeth Medan dan dapat menjadi referensi untuk peningkatan pembelajaran bagi mahasiswa/i dan saran bagi Peneliti Selanjutnya diharapkan agar peneliti selanjutnya dapat meneliti Hubungan Response Time Perawat dengan tingkat kepuasan pasien pada dimensi Tangible di IGD, serta sebagai referensi untuk peneliti selanjutnya dan sebagai sumber pustaka.

\section{Daftar Pustaka}

BPJS Kesehatan. (2017). Peranan BPJS Kesehatan Dalam Peningkatan Pelayanan Kesehatan. Jurnal Rakerkesnas: BPJS Kesehatan.

Hutapea, A.; Daraphonna, C. (2017). Hubungan Penatalaksanaan Gawat Darurat Dengan Waktu Tanggap (Respon time) Keperawatan di Ruang Instalasi Gawat Darurat Rumah Sakit Santa Elisabeth Medan. Jurnal Kesehatan STIKes Santa Elisabeth Medan Vol. 6 No.1(4).

Kaban W.; Kandou G. D; Lapian L. H. (2015). Kepuasan Pasien di Instalasi Gawat Darurat RSUP Prof. Dr. R. D. Kandou Manado. E-journal Keperawatan Vol. 3 No.2.

Keputusan Menteri Kesehatan Republik Indonesia. (2009). Standar Instalasi Gawat Darurat (IGD) Rumah Sakit. Jakarta: Menteri Kesehatan Republik Indonesia.

Liputan 6 (2017). Djarot Minta RS Mitra Keluarga Kalideres di Evaluasi 
Kembali,

(online).

http://news.liputan6.com/read/308

9851/djarot-minta-rs-mitra-

keluarga-kalideres-dievaluasi-

kembali? source $=$ search. diakses

29 September 2017, pukul 17.00 WIB.

Maatilu, Vitrise; Mulyadi; Malara R.T. (2014). Faktor-Faktor Yang Berhubungan Dengan Response Time Perawat Pada Penanganan Pasien Gawat Darurat Di IGD RSUP Prof. Dr. R. D. Kandou Manado. Univ.Sam Ratulangi Manado. E-journal Keperawatan Vol. 3 .

Menteri Kesehatan RI. (2010). Peraturan Menteri Kesehatan Republik Indonesia. Nomor 340/MENKES/PER/III/2010.

Nursalam. (2016). Metodologi penelitian Ilmu Keperawatan. Jakarta: Salemba Medika

(2016). Manajemen Keperawatan edisi kelima. Jakarta: Salemba Medika.

Pisu, Hermawan D.; Rompas S.; Malara R. (2015). Hubungan Response Time Perawat Dengan Tingkat Kepuasan Pasien di Instalasi Gawat Darurat RSUP Prof. Dr. R. D. Kandou Manado. E-journal Keperawatan Vol.3 No.2.

Rekam Medis RSE (2017). Data Pasien BPJS Yang Berobat di IGD Rumah Sakit Santa Elisabeth Medan 2017. Medan

Rimawati; Putra W. K. (2016). Gambaran Kepuasan Pasien Bpjs Terhadap Pelayanan Kesehatan. Jurnal Keperawatan Volume 9(7).

Sondari, A.; Raharjo B.B. (2017). Tingkat Kepuasan Pasien Rawat Jalan Peserta Jaminan Kesehatan Nasional (JKN). HIGEIA 1(1)(2017).

Suhartati et al. (2011). Standar Pelayanan Keperawatan Gawat Darurat di Rumah Sakit. Jakarta: Kementrian Kesehatan

Ulinuha, F. (2014). Kepuasan Pasien BPJS (Badan Penyelenggara
Jaminan Sosial) Terhadap Pelayanan Di Unit Rawat Jalan (Urj) Rumah Sakit Permata Medika Semarang Tahun 2014. Ejournal Keperawatan Vol.2. 